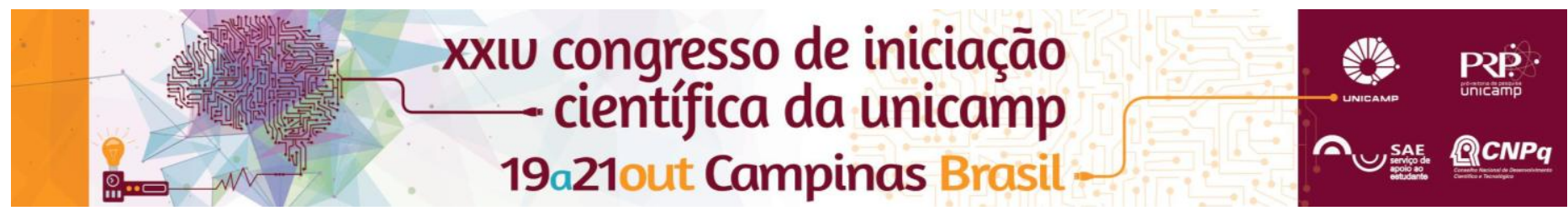

\title{
OTIMIZAÇÃO DE PARÂMETROS SENSORIAIS DE BEBIDA ESPORTIVA CONTENDO PROBIÓTICO, POLPA DE ROMÃ E ISOLADO PROTÉICO DO SORO DE LEITE.
}

\author{
Luciana de Carvalho Fino*, Fabíola L. Pena, Gabriella R. F. Inacio, Priscila T. Sakamae, Fernanda M. Chaves, \\ Thais R. Silva, Adriane E. C. Antunes
}

\begin{abstract}
Resumo
A romã é uma fruta com alto poder antioxidante devido à presença de compostos fenólicos e quando adicionada em outros produtos, como o leite fermentado, pode conferir benefícios para praticantes de exercícios físicos. Com isso, o presente trabalho buscou garantir a segurança microbiológica dos ingredientes e da bebida desenvolvida, assim como proporcionar a otimização sensorial do produto e analisar a composição centesimal do suco de romã adicionado à formulação. Os sucos de romã extraídos, os aditivos e o próprio leite fermentado foram submetidos a análises para detecção de coliformes a $35^{\circ}$ e $45^{\circ} \mathrm{C}$, aeróbios mesófilos, bolores, leveduras e Salmonella. sp., e todos estavam de acordo com a legislação RDC $n^{\circ} 12$, garantindo a segurança da bebida. Analisou-se a composição centesimal do suco de romã, contendo $14^{\circ}$ Brix; $\mathrm{pH} 3,42 ; 1,06 \%$ de ácido cítrico; 0,37\% de cinzas; $83.97 \%$ de umidade; 2,52\% de proteína; $3,56 \%$ de frutose; $8,16 \%$ de glucose; $9,53 \mathrm{nM}$ de fenólicos totais. Para a melhoria sensorial do produto realizou-se um teste de ordenação por preferência, obtendo a seleção do corante e aromatizante preferidos na bebida. Assim sendo, o produto é seguro para o consumo humano, possui elevada quantidade de fenólicos, e será otimizado do ponto de vista sensorial nas próximas etapas da pesquisa.
\end{abstract}

\section{Palavras-chave:}

Romã, leite fermentado, ordenação por preferência.

\section{Introdução}

O consumo regular de leites fermentados contendo probióticos, associado a um estilo de vida saudável trazem alguns benefícios a quem os consome, como controle da microbiota intestinal, estímulo do sistema imune e prevenção de desordens intestinais como diarreia e Síndrome do Intestino Irritável. A adição do suco de romã no produto confere ação antioxidante a este, devido às altas concentrações de fenólicos que possuem influências na atenuação da formação de lesões nas paredes arteriais e na modulação de respostas anti-inflamatórias. E para garantir a segurança da bebida formulada, é necessário estar de acordo com os parâmetros estabelecidos pela resolução $\mathrm{RDC} \mathrm{N}^{\circ} 12$, aprovada em 2001 pela ANVISA.

O presente trabalho buscou avaliar a segurança microbiológica das matérias primas e do produto final desenvolvido, bem como obter otimização sensorial da bebida e analisar a composição centesimal do suco de romã empregado na formulação.

\section{Resultados e Discussão}

$\mathrm{Na}$ avaliação microbiológica dos sucos de romã extraídos por liquidificador e despolpadeira, percebe-se que ambos estão adequados para o estabelecido pela RDC $n^{\circ} 12$ para coliformes a $45^{\circ} \mathrm{C}$ assim como a ausência de Salmonella. A presença de aeróbios mesófilos, bolores ou leveduras foi detectada em pequenas quantidades, porém o tratamento térmico no suco de romã $\left(a 2^{\circ} \mathrm{C}\right.$ por 30 a 40 segundos) seguido de resfriamento imediato, antes da adição na formulação do leite fermentado, eliminou consideravelmente 0 número de microrganismos ali presentes, mostrando-se seguro para o consumo humano. Da mesma maneira, há segurança em adicionar os aditivos (corante e aromatizante) na bebida após a fermentação, visto que todos apresentaram contagens microbianas abaixo do limite de detecção dos métodos.

Tabela 1. Contagens microbiológicas das amostras. DOI: 10.19146/pibic-2016-50696

\begin{tabular}{|c|c|c|c|c|c|}
\hline \multirow[b]{2}{*}{ Amostra } & \multicolumn{5}{|c|}{ Microrganismos analisados } \\
\hline & $\begin{array}{l}\text { Aeróbios } \\
\text { Mesófilos } \\
\text { (UFC. mL-1) }\end{array}$ & $\begin{array}{l}\text { Bolores/ } \\
\text { Leveduras } \\
\text { (UFC. } \text { mL-1) }^{-1}\end{array}$ & $\begin{array}{l}\text { Samonella } \\
\text { sp. }\end{array}$ & $\begin{array}{c}\text { Coliformes a } \\
35^{\circ} \mathrm{C} \\
\text { (NMP.mL-1) }\end{array}$ & $\begin{array}{c}\text { Coliformes a } \\
45^{\circ} \mathrm{C} \\
\text { (NMP.mL-1) }\end{array}$ \\
\hline Suco de romã obtido & $1,7 \times 10^{1}$ & $2,3 \times 10^{1}$ & Ausente & 0,92 & 0,92 \\
\hline Suco de romã obtido & $3,6 \times 10^{2}$ & $3,8 \times 10^{3}$ & Ausente & $<0,3$ & $<0,3$ \\
\hline $\begin{array}{c}\text { Aromatizante Frutas } \\
\text { Vermelhas "Sweet } \\
\text { Mix" }\end{array}$ & $<10$ & $<10$ & Ausente & $<0,3$ & $<0,3$ \\
\hline Corante Vermelho & $<10$ & $<10$ & Ausente & $<3,0$ & $<3,0$ \\
\hline $\begin{array}{l}\text { Emulsão Frutas } \\
\text { Vermelhas "Sweet } \\
\text { Mix" }\end{array}$ & $<10$ & $<10$ & Ausente & $<0,3$ & $<0,3$ \\
\hline $\begin{array}{l}\text { Bebida probiótica } \\
\text { com romã }\end{array}$ & - & $<10$ & - & $<3,0$ & $<3,0$ \\
\hline
\end{tabular}

O leite fermentado também foi submetido a avaliações microbiológicas estando de acordo com a RDC $n^{\circ} 12$. A quantidade de probióticos viáveis de Bifidobacterium animalis subsp. lactis (Bb12) presente na bebida formulada é de $2 \times 10^{8} \mathrm{UFC} / \mathrm{ml}$ do produto, totalizando $2,8 \times 10^{10}$ UFC em $140 \mathrm{ml}$. Analisou-se ainda a composição centesimal do suco de romã extraído por despolpadeira de frutas, apresentando $14^{\circ}$ Brix; $\mathrm{pH} 3,42 ; 1,06 \%$ de ácido cítrico; $0,37 \%$ de cinzas; $83.97 \%$ de umidade; $2,52 \%$ de proteína; $3,56 \%$ de frutose; $8,16 \%$ de glucose; $9,53 \mathrm{nM}$ de fenólicos totais. Para conferir uma melhoria sensorial na bebida, foi realizado um teste de ordenação por preferência, em que os provadores indicaram os corantes e aromatizantes preferidos para adição no produto final.

\section{Conclusões}

O produto desenvolvido é seguro para o consumo humano, estando de acordo com a resolução RDC $n^{\circ} 12$, possui elevada quantidade de fenólicos devido à adição do suco de romã e será otimizado do ponto de vista sensorial nas próximas etapas da pesquisa.

Antunes SMML. Probióticos: agentes promotores de saúde Rev. Soc. Br. Al. Nut. 2007:32(3):113-132

Brasil, 2001. Agência Nacional de Vigilância Sanitária. Resolução - RDC № 12, de 2 de janeiro de 2001.

Jardini F. Avaliação da atividade antioxidante em diferentes extratos da polpa e sementes da romã (Punica granatum, L.). Rev. $\mathrm{Br}$. Cien. Far. 2007:43(1):137-138 